\title{
Dissolution Kinetics: Catalysis by Salts
}

\author{
W. E. KLINE ${ }^{1}$ AND H. S. FOGLER \\ Department of Chemical Engineering, University of Michigan, Ann Arbor, Michigan 48109
}

Received April 11, 1980; accepted October 14, 1980

\begin{abstract}
The dissolution of silicate minerals by hydrofluoric acid has been found to be catalyzed by salts such as $\mathrm{NH}_{4} \mathrm{Cl}, \mathrm{NaCl}$, and $\mathrm{LiCl}$ as well as by strong acids. This catalysis is a strong function of $\mathrm{pH}$ and is attributed to the competitive adsorption of cations at surface hydroxyls. A kinetic model has been developed which represents the dissolution process as a combination of parallel uncatalyzed and catalyzed reactions. The model gives excellent agreement with initial rates of dissolution for kaolinite and quartz, obtained by experiments with a slurry reactor.
\end{abstract}

\section{INTRODUCTION}

During the past several years this laboratory has studied the dissolution of silicate minerals by hydrofluoric acid. One of the significant results of this work has been the determination that these reactions constitute a catalyzed system. In a previous paper (1), it was shown that the hydrofluoric acid dissolution of silicates is catalyzed substantially (as much as $900 \%$ ) by the presence of strong acids such as $\mathrm{HCl}$. This catalysis was attributed to the protonation of surface sites by the adsorption of $\mathrm{H}^{+}$ions. Kinetic rate laws were determined which show that the catalyzing effect of any strong acid may be related to its activity in the bulk solution by means of a Langmuir adsorption isotherm. It was shown that the magnitude of catalysis is a strong function of the nature of the mineral surface, thus suggesting possible applications in the field of selective dissolution from mixed mineral media.

Continuation of this work has resulted in an even more exciting breakthrough in which a similar catalytic effect by neutral salts such as $\mathrm{NH}_{4} \mathrm{Cl}, \mathrm{NaCl}$, and $\mathrm{LiCl}$ has been described. The fact that electrolytes other than acids also increase the rates of silicate dissolution is not well known, and the literature

\footnotetext{
${ }^{1}$ Present Address: Exxon Production Research, Houston, TX.
}

consists of only a few sketchy references to the dissolution of quartz. Iler (3) and Van Lier et al. (4) observed qualitatively that the attack of quartz by strong acids is enhanced by the presence of salts, while Kamiya and Shimokata (5) showed that these rate increases are a function of $\mathrm{pH}$. The fact that these salts also increase the rates by which silicates are dissolved in hydrofluoric acid solutions was reported by Palmer (6) and Kozhevnikov et al. (7), who noted only that the presence of ammonium salts increases the rate of dissolution of quartz by as much as $100 \%$. No explanation or characterization of the phenomenon has been offered until now.

This paper provides a description of the manner in which salts catalyze the hydrofluoric acid dissolution of quartz and kaolinite clay. The results are discussed in three parts. First, experimental data are presented to quantify the catalytic effect and identify the determining parameters. Next, a kinetic model is developed based on adsorption and parallel surface reactions. Finally, the parameters that characterize the model are evaluated and interpreted, and the model is tested.

\section{EXPERIMENTAL}

The rates at which silicate minerals dissolve in hydrofluoric acid, hydrochloric 


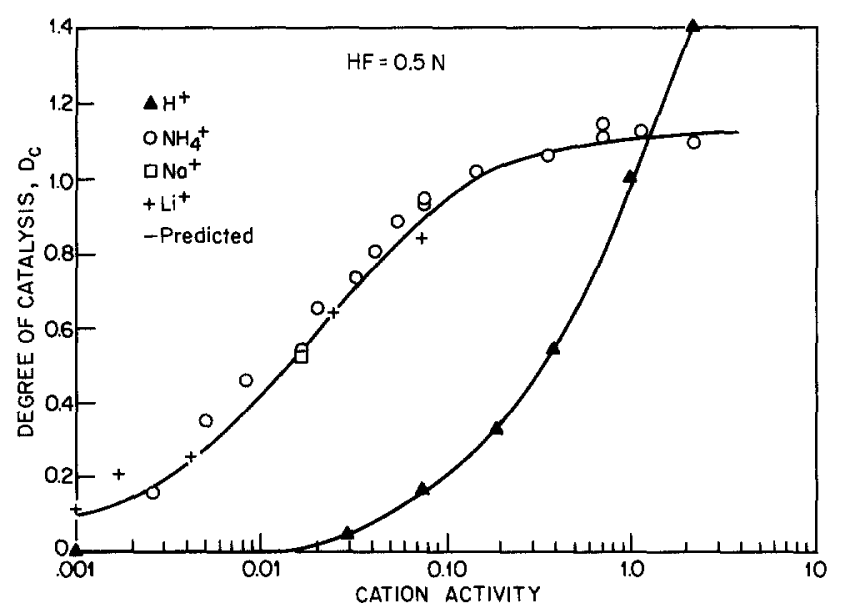

FIG. 1. Catalysis of hydrofluoric acid dissolution of kaolinite at $25^{\circ} \mathrm{C}$.

acid, and salts were measured using a slurry reactor technique discussed previously (1). The progess of dissolution was followed by analyzing slurry filtrate samples for dissolved lattice components as a function of time. It has been shown $(1,2)$ that when silicates are dissolved by hydrofluoric acid the dissolution rates with respect to aluminum and silicon correspond in all cases to their relative stoichiometric ratios within the mineral lattice.

The chemical nature of the system severely limits the number of salts that can be tested for catalytic activity. All of the divalent cations form insoluble fluoride precipitates in HF solutions. Likewise, even monovalent cations such as sodium and potassium form precipitates $(8)$ with the reaction product fluoride complexes (i.e., $\mathrm{K}_{3} \mathrm{AlF}_{6}, \mathrm{~K}_{2} \mathrm{SiF}_{6}$, $\mathrm{NaAlF}_{6}, \mathrm{Na}_{2} \mathrm{SiF}_{6}$ ). Therefore the bulk of the experiments in which salt catalysis was investigated used ammonium salts, which form the most soluble product complexes. The problem of precipitation also imposes limitations on the investigation of salt catalysis as a function of the concentration of $\mathrm{H}^{+}$. Ammonium fluoride is used to suppress the dissociation of $\mathrm{HF}$ to $\mathrm{H}^{+}$and $\mathrm{F}^{-}$. It was found, however, that precipitation resulted at $\mathrm{NH}_{4}^{+}$concentrations greater than $4 \mathrm{~g}$ moles/liter. Hence the minimum concentra- tion of $\mathrm{H}_{3} \mathrm{O}^{+}$at which dissolution rates could be measured was of the order of $10^{-4}$ molar.

The pure component activities used in this work were obtained by multiplying the molal concentrations by molal activity coefficients obtained from literature tabulations $(9,10)$. The activity coefficients in mixtures of electrolytes were calculated from correlations given by Harned (10).

\section{DESCRIPTION OF THE CATALYTIC EFFECT IN MIXTURES OF HYDROFLUORIC ACID AND SALTS}

The manner in which salts catalyze silicate dissolution reactions was investigated by initial rate experiments in which the salt concentration was varied at constant concentrations of the undissociated HF molecule. For each HF concentration, the uncatalyzed rate $-r_{0}$ used as a basis for comparison was evaluated at zero salt concentration and, by extrapolation, at an $\mathrm{H}^{+}$ concentration of zero (1). This procedure is necessary because the presence of $\mathrm{H}^{+}$, even in the small quantities resulting from HF dissociation, also catalyzes the dissolution of silicates. The fraction by which the catalyzed dissolution rate $-r$ is greater than the uncatalyzed rate $-r_{0}$ is defined as the degree of catalysis, $D_{C}$. 


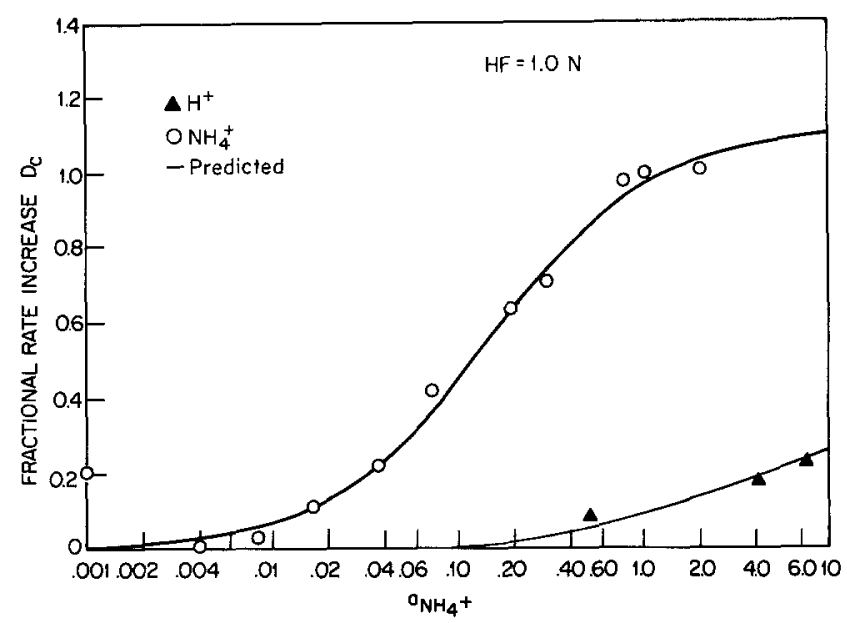

FIG. 2. Catalysis of hydrofluoric acid dissolution of quartz at $60^{\circ} \mathrm{C}$.

$$
D_{\mathrm{C}}=\frac{r}{r_{0}}-1
$$

The increases in silicate dissolution rates resulting from the presence of salts cannot be attributed to independent dissolution by the salts themselves. For short reaction times silicate lattices are virtually impervious to electrolyte solutions which do not contain hydrofluoric acid. In contrast, the amounts by which even small concentrations of salts can increase the rate of attack by $\mathrm{HF}$ are startling. Figures 1 and 2 show the degree of catalysis as a function of the molal activities of $\mathrm{NH}_{4} \mathrm{Cl}$ and $\mathrm{HCl}$ for the dissolution of kaolinite and quartz, respectively. It can be seen that for both minerals the catalysis by $\mathrm{NH}_{4} \mathrm{Cl}$ is substantial at molal activities as low as 0.01 , and that these increases are asymptotic to an upper limit of $D_{\mathrm{C}}=1.1$. For the dissolution of kaolinite the catalysis by $\mathrm{NH}_{4} \mathrm{Cl}$ is greater than the corresponding catalysis by $\mathrm{HCl}$ at low concentrations, while the opposite is true at high concentrations. It has been shown previously (1) that at molal $\mathrm{HCl}$ activities greater than 25 , the $\mathrm{HCl}$ catalysis of kaolinite dissolution becomes asymptotic to an upper limit of $D_{\mathrm{C}}=5.0$. The salt catalysis of the hydrofluoric acid dissolution of quartz, on the other hand, was observed to always be greater than or equal to the catalysis by strong acids. The maximum values of the degree of catalysis are the same for both $\mathrm{NH}_{4} \mathrm{Cl}$ and $\mathrm{HCl}$, but for $\mathrm{HCl}$ this upper limit is approached only at very large hydrogen ion activities $\left(a_{\mathrm{H}}>100\right)$.

As can be seen from Fig. 3, the catalytic effect of ammonium chloride is independent of the concentration of HF. At any fixed concentration of $\mathrm{H}^{+}$, the fraction by which a given concentration of $\mathrm{NH}_{4} \mathrm{Cl}$ increases the rate of dissolution of a given silicate is always the same, regardless of the concentration of $\mathrm{HF}$ and the uncatalyzed rate $-r_{0}$. This independence indicates that the catalysis cannot be explained by a "salting out" effect whereby the presence of an electrolyte decreases the solubility of free $\mathrm{HF}$ and hence increases its activity. If this were the case the increases in the rates of dissolution would be a function of the concentration of $\mathrm{HF}$, a dependence that is not observed. Instead, the origin of the observed catalysis is believed to result from adsorption of the catalyzing ions on the silicate surfaces. It has been shown previously (1) that the degree of catalysis in systems catalyzed by strong acids is also independent of the concentration of $\mathrm{HF}$. This catalysis 


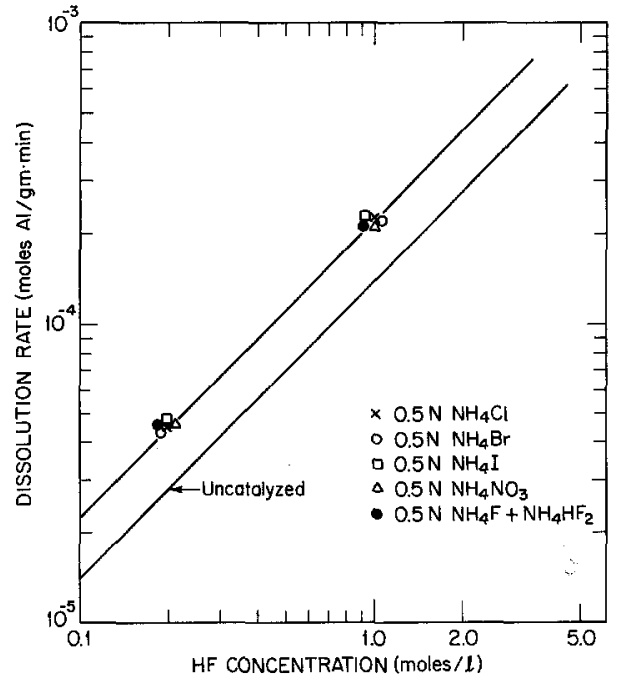

Fig. 3. Comparison of the effects of various ammonium salts on the dissolution of kaolinite at $25^{\circ} \mathrm{C}$.

was described by a kinetic model based on the independent adsorption of $\mathrm{HF}$ and $\mathrm{H}^{+}$ at different sites. The rate laws which describe each of the other possible mechanisms of adsorption and surface reaction are characterized by cross terms representing the catalysis as a function of the concentration of HF.

It can be seen from Fig. 3 that the increases in reaction rates resulting from the presence of a number of different ammonium salts are virtually identical. Consequently the observed catalysis is independent of the identity of the anion and may be wholly attributed to the cation.

As mentioned earlier, dissolution rate experiments in the presence of cations other than $\mathrm{H}^{+}$or $\mathrm{NH}_{4}^{+}$are restricted by precipitation of the reaction products. However, a few experiments with sodium and lithium salts were possible at low salt concentrations. The increases in reaction rates (Fig. 1) were the same as those resulting from identical activities of $\mathrm{NH}_{4} \mathrm{Cl}$, indicating that salt catalysis is a function only of the total salt concentration, $\mathrm{MCl}$, rather than the specific cation $\mathbf{M}^{+}$. The unique catalytic effect of the $\mathrm{H}^{+}$ion is attributed to the chemical ad- sorption of protons by hydroxyl groups present at the silicate surfaces (3). In contrast, the adsorption of $\mathrm{NH}_{4}^{+}, \mathrm{Na}^{+}$, and $\mathrm{Li}^{+}$ at the surfaces of kaolinite and quartz is electrostatic (3).

The total cation concentration in slurries of dissolving kaolinite also includes the dissolution products $\mathrm{Al}^{+3}, \mathrm{AlF}^{+2}$, and $\mathrm{AlF}_{2}^{+}$. The total equilibrium concentration of all three of these aluminum cations, however, is always extremely small, and is comprised almost entirely of the monovalent $\mathrm{AlF}_{2}^{+}$ion. Even at the highest total aluminum concentration measured at the end of any given initial rate experiment $(100 \mathrm{ppm})$, it can be shown that the concentration in the form of cations is less than $0.1 \mathrm{ppm}$, or $1.5 \times 10^{-6}$ $\mathrm{cm}$ moles/liter (based on $\mathrm{AlF}_{2}^{+}$). As can be seen from Figs. 1 and 2, the degree of catalysis resulting from a cation concentration of 1.5 $\times 10^{-6} \mathrm{gm} \mathrm{mole} /$ liter is negligible. Hence the description of catalysis as a function of the activity of salts in solution with HF need not account for catalysis by the reaction products.

Catalysis in Mixtures of Hydrofluoric ACId, Hydrochloric ACID, AND SALTS

In hydrofluoric acid solutions containing both strong acids and salts catalysis is effected by both the $\mathrm{H}^{+}$ions and the $\mathrm{M}^{+}$ions. If $-r_{\mathrm{H}^{+}}$is the rate of catalyzed dissolution where catalysis is only by $\mathrm{H}^{+}$, the degree of acid catalysis, $D_{\mathrm{AC}}$, is defined as

$$
D_{\mathrm{AC}}=\frac{r_{\mathrm{H}^{+}}}{r_{0}}-1 \text {. }
$$

Since an equilibrium concentration of dissociated HF is always present in solutions of hydrofluoric acid, any measured rate of dissolution will be catalyzed to some extent by $\mathrm{H}^{+}$. (Recall that the uncatalyzed rate $-r_{0}$ represents a limit obtained by extrapolation.) Therefore the degree of salt catalysis, $D_{\mathrm{sc}}$, is defined as the fraction by which salt catalysis increases the rate of dissolution beyond the rate of dissolution in a cor- 


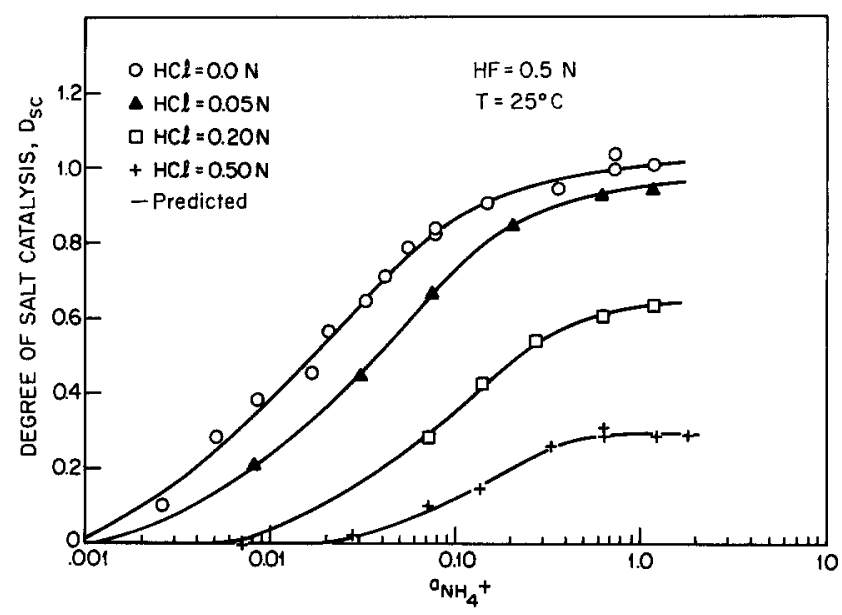

FIG. 4. Degree of salt catalysis of kaolinite in $\mathrm{HF} / \mathrm{HCl}$ mixtures.

responding $\mathrm{HF}$ solution where $\mathrm{H}^{+}$is the only cation.

$$
D_{\mathrm{SC}}=\frac{r}{r_{\mathrm{H}^{+}}}-1 \text {. }
$$

Consequently, the total catalysis, $D_{\mathrm{C}}$, is related to $D_{\mathrm{AC}}$, and $D_{\mathrm{SC}}$ by the function

$$
D_{\mathrm{C}}=\left(1+D_{\mathrm{AC}}\right)\left(1+D_{\mathrm{SC}}\right)-1 \text {. }
$$

For any given silicate, the degree of acid catalysis, $D_{\mathrm{AC}}$, is a function only of temperature and the activity of the hydrogen ion, $a_{\mathrm{H}}(1)$. The degree of salt catalysis, on the other hand, is a function of temperature, the activity of the salt cation, $a_{\mathrm{M}}$, and the hydrogen ion activity. The dependence of the degree of salt catalysis on $a_{\mathrm{H}}$ is illustrated in Fig. 4, which shows the degree of salt catalysis as a function of the activity of the ammonium ion at various concentrations of $\mathrm{HCl}$. In $0.5 \mathrm{~N}$ HF the degree of salt catalysis at large concentrations of salt, $D_{\mathrm{Sc}^{\infty}}$, is 1.0. In a solution of $0.5 \mathrm{~N} \mathrm{HF}$ containing $0.5 \mathrm{~N} \mathrm{HCl}$, on the other hand, the asymptotic limit $D_{\mathrm{Sc}^{\infty}}$ is only 0.3 . The trend by which $D_{\mathrm{SC}}$ decreases as the activity of the hydrogen ion is increased is shown in detail by Fig. 5. One observes that there exists a molal hydrogen ion activity $\hat{a}_{\mathrm{H}}\left(\hat{a}_{\mathrm{H}}\right.$ $=0.72$ for the dissolution of kaolinite at $25^{\circ} \mathrm{C}$ ) where the degree of salt catalysis is reduced to zero at any concentration of salt. The parameter $\hat{a}_{\mathrm{H}}$ is termed the point of zero salt catalysis.

The description of the catalysis by mixtures of strong acids and salts is made even more complex by the fact that the limiting value of the total degree of catalysis at large concentrations of salt, $D_{\mathrm{C}^{\infty}}$, is independent of the hydrogen ion activity. In Fig. 6 one notes that the limiting value $D_{\mathrm{C}^{\infty}}$ is equal to 1.1 for the dissolution of kaolinite in $0.5 \mathrm{~N}$ $\mathrm{HF}$ as well as in solutions of $0.5 \mathrm{~N} \mathrm{HF}$ and $0.5 \mathrm{~N} \mathrm{HCl}$. This limit can be related to $\hat{a}_{\mathrm{H}}$, the hydrogen ion activity at which the degree of salt catalysis goes to zero. Since

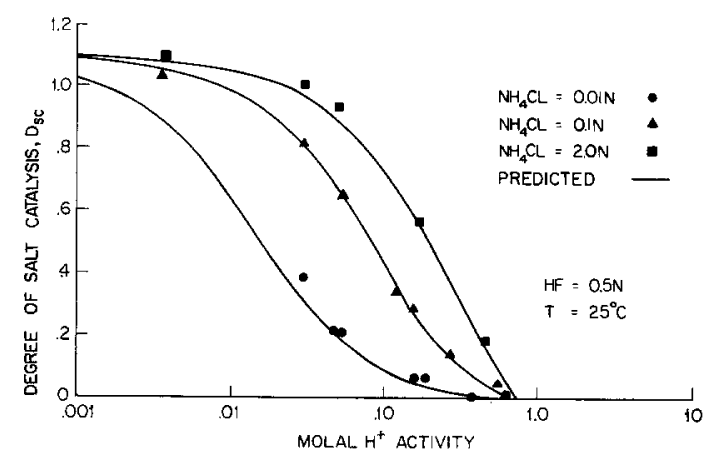

FIG. 5. Degree of salt catalysis of kaolinite as a function of the hydrogen ion activity. 


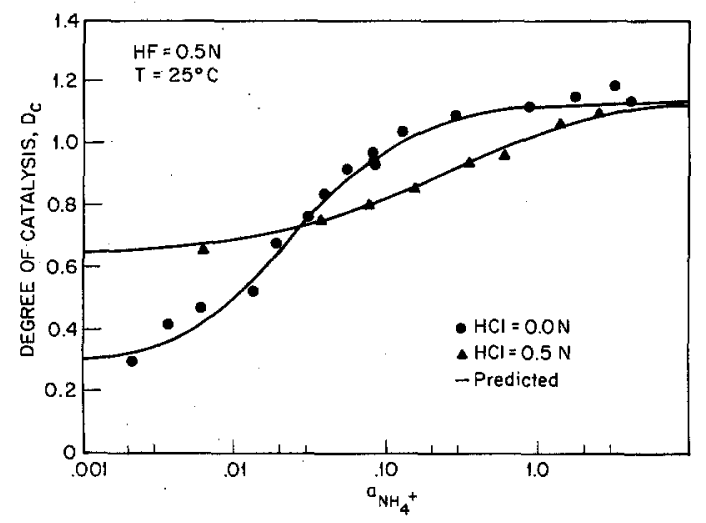

FrG. 6. Overall catalysis of kaolinite dissolution by mixtures of $\mathrm{NH}_{4} \mathrm{Cl}$ and $\mathrm{HCl}$ as a function of $a_{\mathrm{NH}_{4}}$.

$$
D_{\mathrm{SC}^{\infty}}=\left(D_{\mathrm{C}^{\infty}}+1\right) /\left(D_{\mathrm{AC}}+1\right)-1
$$

the magnitude of $D_{\mathrm{SC}^{\infty}}$ goes to zero when $D_{\mathrm{AC}}=D_{\mathrm{C}^{\infty}}$. Therefore the point of zero salt catalysis is the hydrogen ion activity at which the catalysis by the $\mathrm{H}^{+}$ions in solution is equal to the limiting value of the total degree of catalysis as the salt concentration goes to infinity.

The important result derived from Figs. 4 through 6 is that the respective catalytic effects of $\mathrm{H}^{+}$ions and salt cations are competitive. This relationship is clearly illustrated by Fig. 7, which shows that the overall catalysis passes through a minimum as the activity of the hydrogen ion is increased. To the left of the minimum, the action of the salt cations dominates the catalysis. To the right of the minimum, it is the catalysis by $\mathrm{HCl}$ that is most important.

The competitive nature of the catalysis of kaolinite and quartz indicates that the action of the salt cations is direct, and not simply an ionic strength effect that enhances the adsorption of hydrogen ions at the constant potential oxide surfaces. Moreover, it can be further concluded that the catalysis is a function of the total charge at the kaolinite or quartz surface, as determined by the concentration of adsorbed cations. This interpretation was confirmed by experiments with sodium montmorillonite clay. The sur- face charge of sodium montmorillonite is dominated by substitutions within the lattice, and is hence virtually independent of ionic strength. It was found that even high salt concentrations did not catalyze the dissolution of these constant surface charge particles.

In addition to fixing the magnitude of the degree of salt catalysis, the activity of the $\mathrm{H}^{+}$ion also determines the manner in which $D_{\mathrm{SC}}$ increases from zero to $D_{\mathrm{SC}^{\infty}}$ as the cation activity $a_{M}$ is increased. This effect is shown in Fig. 8, which plots the fraction of the asymptotic limit of the degree of salt catalysis, $D_{\mathrm{SC}} / D_{\mathrm{SC}^{\infty}}$, as a function of the activity of the ammonium ion for kaolinite dissolution at $25^{\circ} \mathrm{C}$. It can be seen that the greater the concentration of $\mathrm{H}^{+}$, the greater the concentration of salt required to attain a given fraction of the limit $D_{\mathrm{Sc}^{\infty}}$.

Figure 8 may be further reduced to the single curve of Fig. 9 by plotting the fraction of the net salt catalysis as a function of the ratio of the $\mathrm{NH}_{4}^{+}$and $\mathrm{H}^{+}$activities, $a_{\mathrm{M}} / a_{\mathrm{H}}$. The resulting normalized curve is well represented by an equation of the form:

$$
\frac{D_{\mathrm{SC}}}{D_{\mathrm{SC} \infty}}=\frac{K\left(a_{\mathrm{m}} / a_{\mathrm{H}}\right)}{1+K^{\prime}\left(a_{\mathrm{m}} / a_{\mathrm{H}}\right)} .
$$

This same relationship can be derived from first principles by coupling the surface reaction kinetics with the well-known site building model of adsorption at oxide surfaces.

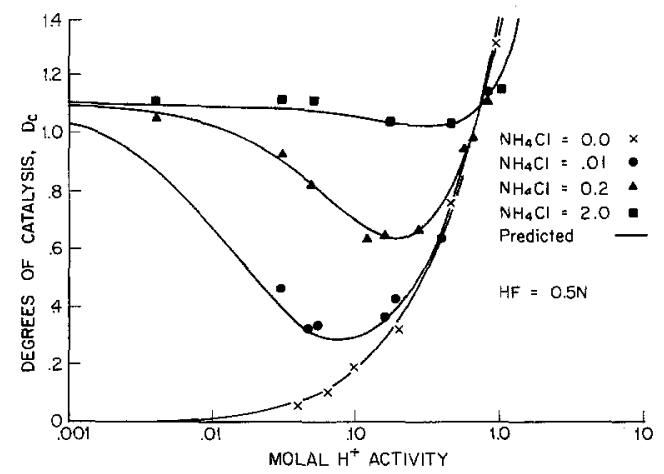

FIG. 7. Overall catalysis of kaolinite dissolution by mixtures of $\mathrm{NH}_{4} \mathrm{Cl}$ and $\mathrm{HCl}$ as a function of $a_{\mathrm{H}}$. 


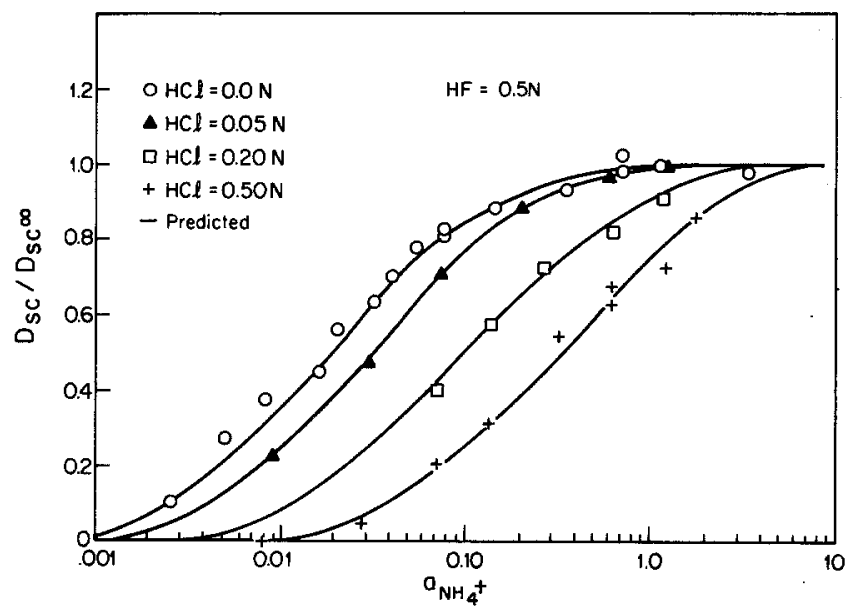

FIG. 8. Fraction of the asymptotic limit of salt catalysis as a function of $a_{\mathrm{NH}_{4}}{ }^{+}$for kaolinite at $25^{\circ} \mathrm{C}$.

DERIVATION OF THE KINETIC MODEL

Since the HF molecules and the catalyzing cations are adsorbed independently at different sites, the respective surface equilibria may be considered separately. It has been shown (2) that the uncatalyzed reaction can be represented by a rate law of the form

$$
-r_{0}=\frac{k_{0} K_{\mathrm{A}} a_{\mathrm{HF}}}{1+K_{\mathrm{A}} a_{\mathrm{HF}}}
$$

where $K_{\mathrm{A}}$ is the adsorption equilibrium con- stant for the equilibrium between the HF molecules and the surface, $k_{0}$ is the specific rate constant, and $a_{\mathrm{HF}}$ is the activity of molecular HF.

It has been established that the adsorption of cations at the surfaces of quartz (1114) and kaolinite (15) take place at surface hydroxyls. As a result of dissociation or adsorption, these $-\mathrm{OH}$ groups can assume a negative, neutral, or a positive charge. Letting $X$ represent either aluminum or silicon, therefore, we can identify four different sites in equilibrium with the electrolytes in the bulk.

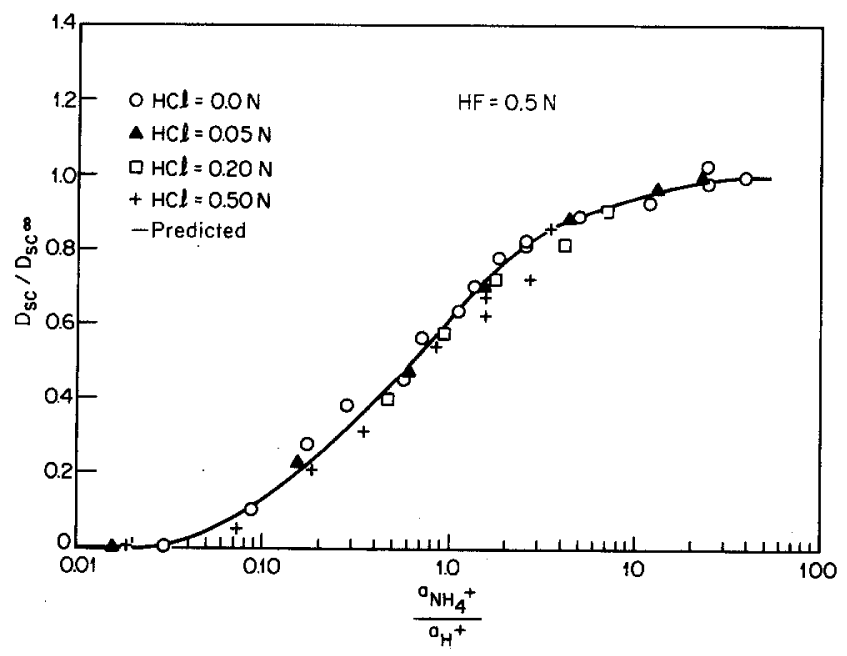

FIG. 9. Fraction of the asymptotic limit of salt catalysis as a function of $a_{\mathrm{NH}_{4}}+a_{\mathrm{H}}$ for kaolinite at $25^{\circ} \mathrm{C}$. 


$$
s^{-}=\begin{gathered}
0^{-} \\
\stackrel{1}{1}-0 \\
0-0
\end{gathered}
$$

$$
\begin{aligned}
& s=\begin{array}{c}
O H \\
1 \\
0-x-0
\end{array} \\
& \mathrm{M} \cdot \mathrm{S}=\begin{array}{c}
0^{-} \mathrm{M}^{+} \\
0-\mathrm{X}-\mathrm{X} \\
0
\end{array}
\end{aligned}
$$$$
H \cdot S=\begin{array}{r}
0-X-0 \\
1 \\
\mathrm{OH}_{2}^{+}
\end{array}
$$

Consequently three separate expressions may be written to describe the adsorption of $\mathrm{H}^{+}$and the salt cations $\left(\mathrm{M}^{+}\right)$.

$$
\begin{aligned}
\mathrm{S}^{-}+\mathrm{H}^{+} \leftrightarrows \mathrm{S}, \\
\mathbf{S}+\mathrm{H}^{+} \leftrightarrows \mathrm{H} \cdot \mathrm{S}, \\
\mathbf{S}^{-}+\mathrm{M}^{+} \leftrightarrows \mathrm{M} \cdot \mathrm{S},
\end{aligned}
$$

The surface concentrations are related by the following equations

$$
\begin{aligned}
C_{\mathrm{S}} & =K_{1} a_{\mathrm{H}} C_{\mathrm{S}^{-}}, \\
C_{\mathrm{H} \cdot \mathrm{S}} & =\left(K_{1} a_{\mathrm{H}}\right)\left(K_{2} a_{\mathrm{H}}\right) C_{\mathrm{S}^{-}}, \\
C_{\mathrm{M} \cdot \mathrm{S}} & =K_{3} a_{\mathrm{M}} C_{\mathrm{S}^{-}},
\end{aligned}
$$

where $a_{\mathrm{H}}$ and $a_{\mathrm{M}}$ represent the activities of the $\mathrm{H}^{+}$and $\mathrm{M}^{+}$cations, respectively. The overall adsorption constants $K_{1}, K_{2}$, and $K_{3}$ are lumped parameters which are functions of both the electrostatic surface potential and any other chemical potentials. This simplification is possible owing to the fact that the surface ions are the only portion of the electrical double layer catalyzing the dissolution.

Since the total concentration of sites is given by

$$
C_{\mathrm{T}}=C_{\mathrm{S}^{-}}+C_{\mathrm{S}}+C_{\mathrm{H} \cdot \mathrm{S}} \div C_{\mathrm{M} \cdot \mathrm{S}}
$$

one can write

$$
\begin{aligned}
C_{\mathrm{S}^{-}} & =\frac{C_{\mathrm{T}}}{1+K_{1} a_{\mathrm{H}}\left(1+K_{2} a_{\mathrm{H}}\right)+K_{3} a_{\mathrm{M}}} \\
C_{\mathrm{S}} & =\frac{K_{1} a_{\mathrm{H}} C_{\mathrm{T}}}{1+K_{1} a_{\mathrm{H}}\left(1+K_{2} a_{\mathrm{H}}\right)+K_{3} a_{\mathrm{M}}} \\
C_{\mathrm{H} \cdot \mathrm{S}} & =\frac{K_{1} a_{\mathrm{H}} K_{2} a_{\mathrm{H}} C_{\mathrm{T}}}{1+K_{1} a_{\mathrm{H}}\left(1+K_{2} a_{\mathrm{H}}\right)+K_{3} a_{\mathrm{M}}} \\
C_{\mathrm{M} \cdot \mathrm{S}} & =\frac{K_{3} a_{\mathrm{M}} C_{\mathrm{T}}}{1+K_{1} a_{\mathrm{H}}\left(1+K_{2} a_{\mathrm{H}}\right)+K_{3} a_{\mathrm{M}}}
\end{aligned}
$$

The adsorption constants $K_{1}$ describe the acidity of the hydroxyl groups associated with aluminum or silicon atoms at the surface. Therefore these constants can be estimated from published pK data (9) for alumina and silicic acid. At $25^{\circ} \mathrm{C}$

$$
\begin{array}{lll}
K_{1}=1.6 \times 10^{11} & \text { if } & \mathrm{X}=\mathrm{Al} \\
K_{1}=5.9 \times 10^{9} & \text { if } & \mathrm{X}=\mathrm{Si}
\end{array}
$$

Even at the smallest concentration of $\mathrm{H}^{+}$ used in these experiments, $10^{-4} \mathrm{gm}$ mole/1, the magnitude of the product $K_{1} a_{\mathrm{H}}$ is very large with respect to unity, and [1 $1+K_{1} a_{\mathrm{H}}(1$ $\left.\left.+K_{2} a_{\mathrm{H}}\right)+K_{3} a_{\mathrm{M}}\right] \cong\left[K_{1} a_{\mathrm{H}}\left(1+K_{2} a_{\mathrm{H}}\right)\right.$ $+K_{3} a_{\mathrm{M}}$.] Hence Eqs. [7] through [10] reduce to

$$
\begin{gathered}
C_{\mathrm{S}^{-}}=\frac{\left(1 / K_{1} a_{\mathrm{H}}\right) C_{\mathrm{T}}}{1+K_{2} a_{\mathrm{H}}+\left(K_{3} / K_{1}\right)\left(a_{\mathrm{M}} / a_{\mathrm{H}}\right)}, \\
C_{\mathrm{S}}=\frac{C_{\mathrm{T}}}{1+K_{2} a_{\mathrm{H}}+\left(K_{3} / K_{1}\right)\left(a_{\mathrm{M}} / a_{\mathrm{H}}\right)}, \\
C_{\mathrm{H} \cdot \mathrm{S}}=\frac{\left(K_{2} a_{\mathrm{H}}\right) C_{\mathrm{T}}}{1+K_{2} a_{\mathrm{H}}+\left(K_{3} / K_{1}\right)\left(a_{\mathrm{M}} / a_{\mathrm{H}}\right)}, \\
C_{\mathrm{M} \cdot \mathrm{S}}=\frac{\left(K_{3} / K_{1}\right)\left(a_{\mathrm{M}} / a_{\mathrm{H}}\right)}{1+K_{2} a_{\mathrm{H}}+\left(K_{3} / K_{1}\right)\left(a_{\mathrm{M}} / a_{\mathrm{H}}\right)} .
\end{gathered}
$$

Due to the fact that the product $K_{1} a_{\mathrm{H}}$ is always large, it can be seen from Eq. [11] that the equilibrium concentration of unoccupied negative sites, $C_{\mathrm{S}^{-}}$, remains very small throughout the experimental range of bulk $\mathrm{H}^{+}$concentrations. Even at the lower limit of $a_{\mathrm{H}}=10^{-4}$, for instance, the equilibrium fraction $C_{\mathrm{S}^{-}} / C_{\mathrm{T}}$ is less than $10^{-5}$. Upon the addition of strong acids to the bulk solution, therefore, virtually all of the adsorbed $\mathrm{H}^{+}$ results in the formation of $\mathrm{H} \cdot \mathrm{S}$ sites. All of the adsorbed $\mathrm{M}^{+}$cations, of course, result in the formation of $\mathrm{M} \cdot \mathrm{S}$ sites.

Consequently one can write two separate kinetic expressions for the catalyzed reactions that superimpose upon the uncatalyzed reaction rate $-r_{0}$. The catalyzed reactions are taken to be proportional to the concentrations of sites occupied by HF and the concentrations of sites occupied by adsorbed $\mathrm{H}^{+}$ and $\mathbf{M}^{+}$ions, respectively. 


$$
\begin{aligned}
& -r_{1}=k_{1} C_{\mathrm{HF} \cdot \mathrm{S}^{\prime}} C_{\mathrm{H} \cdot \mathrm{S}}=\frac{k_{1}\left(K_{\mathrm{A}} a_{\mathrm{HF}}\right)\left(K_{2} a_{\mathrm{H}}\right)}{\left(1+K_{\mathrm{A}} a_{\mathrm{HF}}\right)\left(1+K_{2} a_{\mathrm{H}}+\left(K_{3} / K_{1}\right)\left(a_{\mathrm{M}} / a_{\mathrm{H}}\right)\right)} \\
& -r_{2}=k_{2} C_{\mathrm{HF} \cdot \mathrm{S}^{\prime}} C_{\mathrm{M} \cdot \mathrm{S}}=\frac{k_{2}\left(K_{\mathrm{A}} a_{\mathrm{HF}}\right)\left(\frac{K_{3}}{K_{1}} \frac{a_{\mathrm{M}}}{a_{\mathrm{H}}}\right)}{\left(1+K_{\mathrm{A}} a_{\mathrm{HF}}\right)\left(1+K_{2} a_{\mathrm{H}}+\frac{K_{3}}{K_{1}} \frac{a_{\mathrm{M}}}{a_{\mathrm{H}}}\right)}
\end{aligned}
$$

The overall rate of dissolution is given by the sum of the uncatalyzed and catalyzed reaction rates.

or

$$
-r_{\text {overall }}=-r_{0}+-r_{1}+-r_{2}
$$

$$
\begin{aligned}
& -r_{\text {overall }}=\frac{k_{0} K_{\mathrm{A}} a_{\mathrm{HF}}}{1+K_{\mathrm{A}} a_{\mathrm{HF}}} \\
& \times\left(1+\frac{\frac{k_{1}}{k_{0}} K_{2} a_{\mathrm{H}}+\frac{k_{2}}{k_{0}} \frac{K_{3}}{K_{1}} \frac{a_{\mathrm{M}}}{a_{\mathrm{H}}}}{1+K_{2} a_{\mathrm{H}}+\frac{K_{3}}{K_{1}} \frac{a_{\mathrm{M}}}{a_{\mathrm{H}}}}\right) \text {. }
\end{aligned}
$$

Since the first term of Eq. [17] is simply the uncatalyzed reaction rate, $-r_{0}$, the degree of catalysis $D_{C}$ can be expressed entirely in terms of the activities of the $\mathrm{H}^{+}$ and $\mathrm{M}^{+}$ions.

$$
\begin{aligned}
D_{\mathrm{C}}= & \frac{r}{r_{0}}-1 \\
= & \frac{\frac{k_{1}}{k_{0}} K_{2} a_{\mathrm{H}}+\frac{k_{2}}{k_{0}} \frac{K_{3}}{K_{1}} \frac{a_{\mathrm{M}}}{a_{\mathrm{H}}}}{1+K_{2} a_{\mathrm{H}}+\frac{K_{3}}{K_{1}} \frac{a_{\mathrm{M}}}{a_{\mathrm{H}}}} .
\end{aligned}
$$

While this expression involves six different constants, it is emphasized that each has physical significance with regard to the uncatalyzed and catalyzed reactions. One can also write

$$
D_{\mathrm{AC}}=\frac{r_{\mathrm{H}^{+}}}{r_{0}}-1=\frac{k_{1}}{k_{0}} \frac{K_{2} a_{\mathrm{H}}}{1+K_{2} a_{\mathrm{H}}}
$$

and

$$
D_{\mathrm{SC}}=\frac{r}{r_{\mathrm{H}^{+}}}-1=\frac{\frac{K_{3}}{K_{1}} \frac{a_{\mathrm{M}}}{a_{\mathrm{H}}}\left(\frac{k_{2}}{k_{0}}-\frac{\left(k_{1} / k_{0}\right) K_{2} a_{\mathrm{H}}}{1+K_{2} a_{\mathrm{H}}}\right)}{\left(1+\frac{\left(K_{3} / K_{1}\right)\left(a_{\mathrm{M}} / a_{\mathrm{H}}\right)}{1+K_{2} a_{\mathrm{H}}}\right)\left(1+K_{2} a_{\mathrm{H}}+\frac{k_{1}}{k_{0}} K_{2} a_{\mathrm{H}}\right)} .
$$

One readily observes that the model predicts that the degree of salt catalysis decreases as the activity of the $\mathrm{H}^{+}$ion is increased. Taking the limit of Eq. [20] at very large salt concentrations gives

$D_{\mathrm{SC} \infty}$

$$
=\frac{\left(1+K_{2} a_{\mathrm{H}}\right)\left(\frac{k_{2}}{k_{0}}-\frac{\left(k_{1} / k_{0}\right) K_{2} a_{\mathrm{H}}}{1+K_{2} a_{\mathrm{H}}}\right)}{\left(1+K_{2} a_{\mathrm{H}}+\frac{k_{1}}{k_{0}} K_{2} a_{\mathrm{H}}\right)} .
$$

Dividing Eq. [20] by Eq. [21] gives the fraction of this limiting value of the degree of salt catalysis.

$$
\frac{D_{\mathrm{SC}}}{D_{\mathrm{SC} \infty}}=\frac{\frac{K_{3}}{K_{1}} \frac{a_{\mathrm{M}}}{a_{\mathrm{H}}}}{1+K_{2} a_{\mathrm{H}}+\frac{K_{3}}{K_{1}} \frac{a_{\mathrm{M}}}{a_{\mathrm{H}}}} .
$$

In a previous study of the acid catalyzed dissolution of kaolinite (1) it was shown that the value of the apparent adsorption constant $K_{2}$ is 0.39 at $25^{\circ} \mathrm{C}$. Therefore the magnitude of the term $K_{2} a_{\mathrm{H}}$ in Eq. [22] is less than 0.1 when the $\mathrm{HCl}$ concentration is less than 0.5 $N\left(a_{\mathrm{H}}<0.38\right)$. In this region of small values of $K_{2} a_{\mathrm{H}}$ the expression for the fraction $D_{\mathrm{SC}} / D_{\mathrm{SC}^{\infty}}$ depends only on the ratio, $a_{\mathrm{M}} / a_{\mathrm{H}}$. 


$$
\frac{D_{\mathrm{SC}}}{D_{\mathrm{SC} \infty}}=\frac{\frac{K_{3}}{K_{1}} \frac{a_{\mathrm{M}}}{a_{\mathrm{H}}}}{1+\frac{K_{3}}{K_{1}} \frac{a_{\mathrm{M}}}{a_{\mathrm{H}}}},
$$

which is exactly the functionality indicated by the experimental data in Fig. 9. This simplification of [22] also holds over a wide range of $\mathrm{HCl}$ concentrations for the catalyzed dissolution of quartz, which is characterized by adsorption constants $K_{2}$ yet an order of magnitude smaller than those measured for kaolinite (1).

\section{EVALUATION AND INTERPRETATION OF THE RATE LAW PARAMETERS}

Equation [18] predicts that the total degree of catalysis by mixtures of strong acids and salts is a function of the activity of the $\mathrm{H}^{+}$and $\mathrm{M}^{+}$cations.

$$
D_{\mathrm{C}}=\frac{\frac{k_{1}}{k_{0}} K_{2} a_{\mathrm{H}}+\frac{k_{2}}{k_{0}} \frac{K_{3}}{K_{1}} \frac{a_{\mathrm{M}}}{a_{\mathrm{H}}}}{1+K_{2} a_{\mathrm{H}}+\frac{K_{3}}{K_{1}} \frac{a_{\mathrm{M}}}{a_{\mathrm{H}}}} .
$$

The parameters $k_{1} / k_{0}$ and $K_{2}$, which characterize the catalysis by the $\mathrm{H}^{+}$ion, have been reported previously (1). The ratio of specific rate constants $k_{1} / k_{0}$ can be described as a potential, since this parameter fixes the asymptotic degree of acid catalysis at high

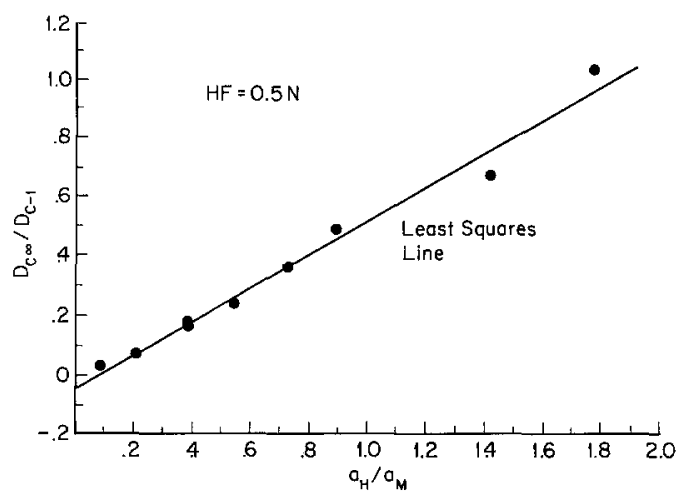

FIG. 10. Linearization of model for dissolution of kaolinite at $25^{\circ} \mathrm{C}$.
TABLE I

Values of the Rate Law Parameters

\begin{tabular}{lccccc}
\hline \multicolumn{1}{c}{ Mineral } & $\begin{array}{c}\text { Tempera- } \\
\text { ture }\end{array}$ & $k_{1} / k_{0}$ & $\begin{array}{c}k_{2} / k_{0} \\
=D_{\mathrm{c}^{\infty}}\end{array}$ & \multicolumn{1}{c}{$K_{2}$} & $K_{3} / K_{1}$ \\
\hline Kaolinite & $25^{\circ} \mathrm{C}$ & 5 & 1.1 & 0.39 & 1.8 \\
Kaolinite & $50^{\circ} \mathrm{C}$ & 5 & 1.1 & 0.18 & 3.3 \\
Quartz & $60^{\circ} \mathrm{C}$ & 1.1 & 1.1 & 0.045 & 0.29
\end{tabular}

concentrations of strong acids. The adsorption constant $K_{2}$ represents the equilibrium between the $\mathrm{H}^{+}$ions and the silicate surface. In an analogous manner, the constants $k_{2} / k_{0}$ and $K_{3} / K_{1}$ describe the catalysis by salts. The ratio of rate constants $k_{2} / k_{0}$ gives the previously described parameter, $D_{\mathrm{C}^{\infty}}$, the asymptotic limit of the total catalysis at very large concentrations of salt. The ratio of equilibrium constants $K_{3} / K_{1}$ describes the competitive adsorption of $\mathrm{M}^{+}$and $\mathrm{H}^{+}$cations.

Substantiation of the rate law given by Eq. [18] is obtained by plotting the data $D_{\mathrm{C}^{\infty}} / D_{\mathrm{C}}-1$ as a function of $a_{\mathrm{H}} / a_{\mathrm{M}}$ at small values of $a_{\mathrm{H}}$. Straight lines were obtained for both kaolinite and quartz at each temperature investigated, as illustrated by Fig. 10 . The values of $K_{3} / K_{1}$ calculated from the slopes, along with the previously determined values of $k_{2} / k_{0}=D_{\mathrm{C}^{\infty}, k_{1}} / k_{0}$, and $K_{2}$ are presented in Table 1.

One notes from Table 1 that the ratios $k_{2} / k_{0}$ and $k_{1} / k_{0}$ are both independent of temperature, indicating that the rate constants $k_{0}, k_{1}$, and $k_{2}$ are characterized by the same apparent activation energy. Several possible explanations were discussed in a previous paper (1), the most likely being that the proton of the $\mathrm{HF}$ molecule plays a role in the uncatalyzed reaction similar to that of the catalyzing $\mathrm{H}^{+}$or $\mathrm{M}^{+}$ions, resulting in similar intermediates.

Another intriguing result is the fact that the maxima $k_{2} / k_{0}$ are the same for kaolinite and quartz. A possible interpretation is that the salt catalysis of the dissolution of kaolinite results totally or predominately from adsorption at the silica sheets. However, 
such a hypothesis cannot be substantiated on the basis of kinetic data. Further investigations such as spectroscopic studies of the surface and of the reactive intermediates are required.

The fact that the ratio of adsorption constants $K_{3} / K_{1}$ is greater than unity for kaolinite implies that the exchange equilibrium

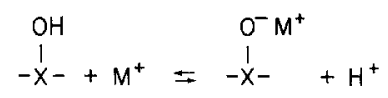

is appreciably shifted to the right even at comparable concentrations of $\mathrm{H}^{+}$and $\mathrm{M}^{+}$. When the ratio $a_{\mathrm{M}} / a_{\mathrm{H}}$ is large, most of the adsorption sites are of the form

$$
\begin{aligned}
& 0^{-} M^{+} \\
& 1 \\
& -X-
\end{aligned}
$$

This finding is consistent with the conclusions of Ferris and Jepson (15) who studied the adsorption of radioactively tagged cations on kaolinite particles. These investigators determined that any ion exchange capacity ascribed to kaolinite may be wholly attributed to adsorption at the surface hydroxyl sites. They found no evidence to support the traditional view (16) that this exchange capacity is primarily a result of isomorphous substitutions within the lattice and broken bonds at the unit cell edges.

Equation [18] can now be used to predict the rates of dissolution in mixtures of hydrofluoric acid, strong acids and salts. The solid curves in Figs. 4 through 9 were calculated by substituting the experimentally determined parameters into Eqs. [18] through [22]. In each case the agreement between the predicted catalysis and the experimental measurements is excellent.

\section{Point of Zero Salt Catalysis}

From Fig. 5 it can be seen that the model predicts the hydrogen ion activity $\hat{a}_{\mathrm{H}}$ at which the degree of salt catalysis goes to zero. This point is determined by Eq. [20], which goes to zero when

$$
\frac{k_{2}}{k_{0}}-\frac{\left(k_{1} / k_{0}\right) K_{2} a_{\mathrm{H}}}{1+K_{2} a_{\mathrm{H}}}=0
$$

or

$$
\hat{a}_{\mathrm{H}}=\frac{1}{K_{2}\left(\left(k_{1} / k_{0} / D_{\mathrm{C}_{\infty}}\right)-1\right)} .
$$

Substituting the appropriate parameters from Table 1 for the dissolution of kaolinite at $25^{\circ} \mathrm{C}$ gives a value of $\tilde{a}_{\mathrm{H}}=0.72$, which is consistent with the point of zero salt catalysis indicated by the experimental data in Fig. 5. Evaluating Eq. [19], the expression for the degree of acid catalysis, at $\hat{a}_{\mathrm{H}}$ gives

$$
D_{\mathrm{AC}}\left(\hat{a}_{\mathrm{H}}\right)=k_{2} / k_{0}=D_{\mathrm{C}^{\infty}}
$$

thus confirming the previous conclusion that at the point of zero salt catalysis the catalysis by the $\mathrm{H}^{+}$ions is equal to the limiting value of the total degree of catalysis as the salt concentration goes to infinity. Salts will no longer increase the rate of dissolution when $D_{\mathrm{AC}}$ is greater than or equal to $D_{\mathrm{C}^{\infty}}$.

One observes further from Eq. [20] that the degree of salt catalysis is negative when $a_{\mathrm{H}}$ is greater than $\hat{a}_{\mathrm{H}}$. The model predicts that the addition of salts to HF solutions containing large concentrations of strong acids can theoretically reduce the total catalysis from $D_{\mathrm{C}}=k_{1} / k_{0}$ to $D_{\mathrm{C}}=k_{2} / k_{0}$, a reduction of $78 \%$ for the dissolution of kaolinite at $25^{\circ} \mathrm{C}$. Consequently, an important experimental test is the manner in which the overall degree of catalysis changes as a function of the concentration of salt at $\mathrm{H}^{+}$activities greater than the point of zero salt catalysis.

Figure 11 compares the catalytic effect of $\mathrm{NH}_{4} \mathrm{Cl}$ in solutions of $0.5 \mathrm{~N} \mathrm{HF}$ mixed with $0.5 \mathrm{~N} \mathrm{HCl}$ (less than the point of zero salt catalysis) and $1.0 \mathrm{~N} \mathrm{HCl}$ (greater than the point of zero salt catalysis) on the dissolution of kaolinite at $25^{\circ} \mathrm{C}$. Since the decrease in the degree of catalysis is a function of the ratio $a_{\mathrm{M}} / a_{\mathrm{H}}$, only small reductions can be observed over the range of practical salt concentrations $(<4 N)$. It can be seen, how- 


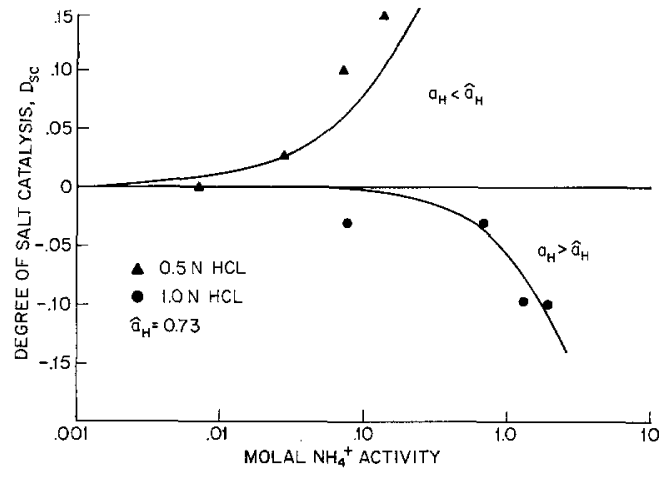

FIG. 11. Effect of adding salts on either side of the point of zero salt catalysis for kaolinite dissolution at $25^{\circ} \mathrm{C}$.

ever, that the prediction of negative catalysis beyond the point of zero salt catalysis is confirmed.

A special case of the relationship between the catalysis by salts and the activity of the hydrogen ion is illustrated by the catalysis of the hydrofluoric acid dissolution of quartz. For quartz it was determined that the asymptotic limit of catalysis by strong acids is the same as the limit reached at very large salt concentrations (i.e., $k_{1} / k_{0}=k_{2} / k_{0}=1.1$ ). From Eq. [23], therefore, it can be seen that the degree of salt catalysis goes to zero only as $a_{\mathrm{H}}$ becomes infinite. Hence the addition of salts to the HF solution will always increase the rate of quartz dissolution, and a finite point of zero salt catalysis does not exist.

As a practical matter, however, the degree to which the salt catalysis of the dissolution of quartz approaches the asymptotic limit is restricted by the fact that the parameter $K_{2} / K_{1}$ is relatively small $(0.29$ at $60^{\circ} \mathrm{C}$ as opposed to 3.3 at $50^{\circ} \mathrm{C}$ for kaolinite). In the presence of $1.0 \mathrm{~N} \mathrm{HCl}$, for example, it can be calculated that a mean molal $\mathrm{NH}_{4} \mathrm{Cl}$ activity of 17 is required before the total catalysis reaches $90 \%$ of the asymptotic limit. Experimentally, however, it was found that the dissolution products begin to precipitate at molal $\mathrm{NH}_{4}^{+}$activities greater than 4 .

\section{SUMMARY}

This investigation has established the significant fact that the catalysis of the hydrofluoric acid dissolution of silicates is not limited to strong acids. Rather, experimental kinetic evidence indicates that the rates of dissolution can also be increased by the surface adsorption of cations such as $\mathbf{N H}_{4}^{+}$, $\mathrm{Na}^{+}$, and $\mathrm{Li}^{+}$. A model was developed that successfully describes the kinetics of the catalyzed dissolution of kaolinite and quartz as the sum of three parallel reactions - uncatalyzed attack by HF molecules and surface reactions catalyzed by $\mathrm{H}^{+}$and salt cations, respectively.

The catalysis by strong acids and salts results from the formation of

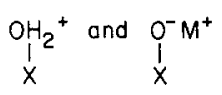

groups by adsorption at surface hydroxyls. The hypothesis that the $\mathrm{H}^{+}$and $\mathrm{M}^{+}$cations are in competition for these sites is supported by the fact that strong acids and salts do not affect the reaction rates independently. The catalytic action of a given concentration of salt is a function of the ratio $a_{\mathrm{M}} / a_{\mathrm{H}}$, and it was shown that the rates of dissolution pass through a minimum when strong acids are added to mixtures of $\mathrm{HF}$ and salts. In addition, a parameter called the point of zero salt catalysis can be identified, which is the hydrogen ion activity at which the net catalysis by any concentration of salts is zero. At $\mathrm{H}^{+}$concentrations less than the point of zero salt catalysis the presence of salts increases the rate of dissolution. At $\mathrm{H}^{+}$concentrations greater than this point the addition of salts actually inhibits the rate of attack.

\section{REFERENCES}

1. Kline, W. E., and Fogler, H. S., J. Colloid Interface Sci. 82, 93 (1981).

2. Kline, W. E., Ph.D. Thesis, University of Michigan, 1980. 
3. Iler, R. K., "The Chemistry of Silica." Wiley, New York, 1979.

4. Van Lier, J. A., de Bruyn, P. L., and Overbeck, Th. G., J. Phys. Chem. 64, 1675 (1960).

5. Kamiya, H., and Shimokata, K., Proc. Int. Symp. Water Rock Int. 1974426 (1976).

6. Palmer, W. G., J. Chem. Soc., 1656 (1930).

7. Kozhevnikov, S., et al., Russ. J. Inorg. Chem. 22, 1850 (1977).

8. Hekim, Y., and Fogler, H. S., Chem. Eng. Sci. 32, 1 (1977).

9. Dean, J. A., ed., "Lange's Handbook of Chemistry," 11th ed. McGraw-Hill, New York, 1973.

0. Harned, H. S., and Owen, B. B., "The Physical
Chemistry of Electrolyte Solutions," 3rd ed. Reinhold, New York, 1958.

11. Busetti, S. G., Tschapek, M., and Helmey, A.K., J. Electroanal. Chem. 36, 507 (1972).

12. Ahrland, S., Grethe, I., and Noren, B., Acta Chem. Scand. 14, 1069 (1960).

13. Tadros, T. F., and Kyklema, J., J. Electroanal. Chem. 22, 1 (1969).

14. Allen, D., Matijevic, E., and Meites, L., J. Colloid Interface Sci. 33, 1293 (1971).

15. Ferris, A. P., and Jepson, W. B., J. Colloid Interface Sci. 51, 245 (1975).

16. Grim, R. E., "Clay Mineralogy," 2nd ed. McGraw-Hill, New York, 1968. 